Published in final edited form as:

Hepatology. 2018 September ; 68(3): 1042-1056. doi:10.1002/hep.29898.

\title{
Blocking $\mathrm{H} 1 / \mathrm{H} 2$ histamine receptors inhibits damage/fibrosis in Mdr2--- mice and human cholangiocarcinoma tumorigenesis
}

\author{
Lindsey Kennedy ${ }^{1,3}$, Laura Hargrove ${ }^{3}$, Jennifer Demieville ${ }^{1}$, Allen Karstens ${ }^{2}$, Hannah \\ Jones $^{2}$, Sharon DeMorrow ${ }^{1,3}$, Fanyin Meng ${ }^{1,2,3}$, Pietro Invernizzi ${ }^{4}$, Francesca Bernuzzi ${ }^{4}$, \\ Gianfranco Alpini $^{1,2,3}$, Steven Smith ${ }^{2}$, Austin Akers ${ }^{2}$, Victoria Meadows ${ }^{1}$, Heather \\ Francis $^{1,2,3}$ \\ ${ }^{1}$ Research, Central Texas Veterans Health Care System, Temple, Texas, USA \\ ${ }^{2}$ Scott \& White Digestive Disease Research Center, Baylor Scott \& White Health, Temple, Texas, \\ USA \\ ${ }^{3}$ Medicine, Texas A\&M Health Science Center, Temple, Texas, USA \\ ${ }^{4}$ Program for Autoimmune Liver Diseases, International Center for Digestive Health, Department \\ of Medicine and Surgery, University of Milan-Bicocca, Monza, Italy
}

\section{Abstract}

\begin{abstract}
Background-Primary Sclerosing Cholangitis (PSC) patients are at risk of developing cholangiocarcinoma (CCA). We have shown that: (i) histamine (HA) increases biliary hyperplasia via $\mathrm{H} 1 / \mathrm{H} 2$ histamine receptors (HRs) and (ii) HA levels increase and mast cells (MCs) infiltrate during PSC and CCA. We aimed to examine the effects of chronic treatment with H1/H2HR antagonists on PSC and CCA.
\end{abstract}

Methods-Wild-type and Mdr2-/- mice were treated by osmotic minipumps with saline, mepyramine or ranitidine $(10 \mathrm{mg} / \mathrm{kg}$ BW/day) or a combination of mepyramine/ranitidine for 4 wks. Liver damage was assessed by H\&E. We evaluated (i) H1/H2 HR expression; (ii) MC presence; (iii) l-histidine decarboxylase (HDC)/HA axis; (iv) cholangiocyte proliferation/bile duct mass (v) fibrosis/hepatic stellate cell (HSC) activation. Nu/nu mice were implanted with MzChA-1 cells into the hind flanks and treated with saline, mepyramine or ranitidine. Tumor growth was measured and we evaluated: (i) $\mathrm{H} 1 / \mathrm{H} 2 \mathrm{HR}$ expression; (ii) proliferation; (iii) MC activation; (iv) angiogenesis and (v) epithelial-mesenchymal transition (EMT). In vitro, human hepatic stellate cells were evaluated for H1HR and H2HR expression. Cultured cholangiocytes and CCA lines were treated with saline, mepyramine or ranitidine $(25 \mu \mathrm{M})$ before evaluating proliferation, angiogenesis, EMT, and potential signaling mechanisms.

Results-H1/H2HR and MC presence increased in human PSC and CCA. In H1/H2HR antagonist (alone or in combination)-treated $\mathrm{Mdr} 2^{-/-}$mice, liver and biliary damage and fibrosis

\footnotetext{
Address correspondence to: Heather Francis, Ph.D., Associate Professor, Department of Medical Physiology | College of Medicine | Texas A\&M University, Central Texas Veteran's Health Care System, Baylor Scott \& White Health, 1901 South $1^{\text {st }}$ Street, Temple, Texas 76504, 254-743-1048, hfrancis@ medicine.tamhsc.edu.

Disclosures: The authors have nothing to disclose. This material is the result of work supported with resources and the use of facilities at the Central Texas Veterans Health Care System, Temple, Texas. The content is the responsibility of the author(s) alone and does not necessarily reflect the views or policies of the Department of Veterans Affairs or the United States Government.
} 
decreased compared to saline treatment. H1/H2HR antagonists decreased tumor growth, serum $\mathrm{HA}$, angiogenesis and EMT. In vitro, $\mathrm{H} 1 / \mathrm{H} 2 \mathrm{HR}$ blockers reduced biliary proliferation, and CCA cells had decreased proliferation, angiogenesis, EMT and migration.

Conclusion-Inhibition of H1/H2HR reverses PSC-associated damage and decreases CCA growth, angiogenesis and EMT. Since PSC patients are at risk of developing CCA, using HR blockers may be therapeutic for these diseases.

\section{Keywords}

Histamine; mast cells; PSC; CCA

\section{Introduction}

Primary sclerosing cholangitis (PSC) is a chronic inflammatory condition that affects both intra- and extra-hepatic cholangiocytes $(1,2)$. In conditions of chronic cholestasis, cholangiocytes proliferate and secrete neuroendocrine factors (3-5) inducing fibrosis via hepatic stellate cell (HSC) activation (6, 7). PSC is characterized by inflammation and is a prominent risk factor for developing cholangiocarcinoma (CCA) $(1,8)$, a devastating liver cancer that has a difficult diagnosis coupled with a significant lack of beneficial therapeutics (1). The risk of developing CCA increases dramatically in patients previously diagnosed with PSC (9) and the link between the two has been attributed to advanced age of diagnosis, smoking, alcohol consumption, genetic alterations and other environmental factors $(8,9)$. Studies to examine the progression of PSC and CCA include the multi-drug resistance gene knockout mouse model of PSC, Mdr2-/- $(7,10,11)$, and xenograft models of CCA using immunocompromised mice $(12,13)$, respectively. $\mathrm{Mdr} 2^{-/-}$mice develop a human-like phenotype of PSC as they age beginning around 4 weeks of age when there is distinct biliary hyperplasia and inflammation $(7,10)$. Fibrosis in $\mathrm{Mdr} 2^{-/-}$mice is present beginning at 4 weeks of age and progresses beyond 12 weeks of age. Interestingly, $\mathrm{Mdr} 2^{-/-}$mice develop hepatocellular carcinoma as they reach one year of age (14). The xenograft model of CCA is used to examine tumor progression, angiogenesis and epithelial-to-mesenchymal transition (EMT) $(12,13)$.

Histamine interacts with one of four G-protein coupled histamine receptors (HRs) to promote liver damage and hepatic fibrosis in human $\mathrm{PSC}, \mathrm{Mdr} 2^{-/-}$mice and in xenograft models of CCA $(7,12,15)(16)$. This inflammatory mediator is secreted by cholangiocytes and regulates autocrine signaling in the biliary tree (15), but is also abundantly secreted by degranulating mast cells (17) demonstrating a paracrine role for mast cells during liver damage. We have shown that mast cells migrate close to bile ducts within the liver following damage including cholestatic injury, PSC progression and CCA development $(5-7,12)$. Further, blocking mast cell activation using cromolyn sodium decreases biliary damage, hepatic fibrosis and CCA growth $(7,12)$. Also, mast cell-deficient mice subjected to bile duct ligation had significantly less damage and fibrosis than wild-type mice, and injection of cultured mast cells into mast cell-deficient mice increased damage and hepatic fibrosis pinpointing mast cells as critical regulators of liver disease (6). 
Chronic usage of HR blockers has significantly increased in the past decade. Patients suffering from allergies, asthma, gastric acid secretion and reflux are consuming large quantities of H1HR and H2HR antagonists like Allegra ${ }^{\circledR}$, Zantac $\AA$, Prilosec $\AA$, and Zyrtec $®$. The H1HR and H2HR are stimulatory receptors that induce a number of biological effects including cellular proliferation (16). Further, H1HR increases small, but not large biliary mass, whereas H2HR agonist treatment increases only large biliary mass (16). We postulate that chronic usage of these drugs may ameliorate PSC-induced hepatic damage and fibrosis as well as reducing CCA tumor growth, angiogenesis and metastasis.

\section{Methods and Materials}

\section{Animal Models}

PSC mouse model-Male WT and Mdr2 $2^{-/}$mice ( 8 weeks of age) were implanted with osmotic minipumps to deliver $0.9 \% \mathrm{NaCl}$ (saline) or $10 \mathrm{mg} / \mathrm{kg} \mathrm{BW} /$ day $(18,19)$ of either mepyramine (H1HR antagonist), ranitidine (H2HR antagonist). In separate experiments, male Mdr2 $2^{-/}$mice ( 8 weeks of age) were treated with a combination of mepyramine and ranitidine (H1HR/H2HR antagonist) for 4 weeks to mimic chronic usage. Male mice ( $8-10$ mice per group) were euthanized at 12 weeks of age, where these mice display an increase in PSC-induced hepatic damage $(7,10)$. From these groups, we collected liver blocks (frozen and paraffin-embedded), serum, cholangiocytes and cholangiocyte supernatants, as described $(7,20)$.

CCA mouse model-For xenograft experiments, male nu/nu mice were implanted with Mz-ChA-1 cells $\left(3 \times 10^{6}\right.$ cells per injection) into both hind flanks allowing for tumor development according to our previous studies $(13,15,21)$. After 10 days of implantation, tumor formation and establishment occurred. Following tumor formation, mice were treated with saline $(\mathrm{NaCl})$, mepyramine or ranitidine $(10 \mathrm{mg} / \mathrm{kg}$ BW/day) $(6$ mice per group $=12$ tumors per group) by IP injection $3 x$ per week for 31 days, along with tumor measurement $\left(\mathrm{mm}^{3}=0.5 \times\right.$ length $(\mathrm{mm}) \times$ width $(\mathrm{mm}) \times$ height $\left.\left.(\mathrm{mm})\right]\right)(13,15,21)$. Then, we collected serum, tissue and excised tumors for frozen and paraffin-embedded processing, as described by us (12).

\section{Human Samples and Tissue Arrays}

Human liver sections from control (obtained from areas of non-diseased livers taken during resection following CCA diagnosis), PSC patients and CCA tissues were utilized. PSC patients presented with a range of early to late stage PSC, as described in our previous work (7). Liver sections ( $4-5 \mu \mathrm{m}$ thick) were obtained by needle biopsies from three control patients, three PSC patients and six CCA patients. Serum samples were obtained from 3 control patients and 3 CCA patients, which were separate from the above patient samples. The de-identified samples were provided by Dr. Pietro Invernizzi (Humanitas Research Hospital, Rozzano, Italy) under a protocol approved by the Ethics Committee of the Humanitas Research Hospital; the protocol was also reviewed by the local Veterans' Administration IRB and R\&D Committee. Human CCA tissue arrays, utilized as described by us $(13,15,21)$, were obtained from Pantomics (Richmond, CA). 
Morphological analysis of chronic H1HR or H2HR blockers in Mdr2-/- miceWe performed $\mathrm{H} \& \mathrm{E}$ in livers from WT and $\mathrm{Mdr} 2^{-/-}$mice that were treated chronically with the H1HR antagonist, H2HR antagonist or combined H1HR/H2HR antagonists to evaluate lobular damage, necrosis and inflammation.

\section{Evaluation of mast cell presence and the HDC/HA/HR axis in PSC and CCA-}

H1HR and H2HR expression was measured by immunohistochemistry in WT mice, Mdr2 $2^{-1-}$ mice, human PSC and CCA (15). Also, HDC expression was evaluated by real-time PCR in all groups following treatment with vehicle, H1HR or H2HR antagonist treatment.

Histamine secretion was evaluated by EIA in serum from all groups of mice and in human serum from control or patients with CCA $(6,7,12)$.

Mast cell presence was measured by immunohistochemistry for mouse mast cell protease-1 (mMCP-1) in Mdr2 ${ }^{-/-}$mice treated with saline or H1HR or H2HR antagonists and toluidine blue staining in tumors from treated nu/nu mice. mRNA expression of c-Kit, chymase and tryptase was measured in livers and tumors from all groups of mice. Real-time PCR was performed using $\Delta \Delta \mathrm{CT}(6,7,12)$.

Measurement of IBDM and proliferation in $\mathrm{Mdr2}^{-/-}$mice treated with $\mathrm{H} 1$ or $\mathrm{H} 2$ HR antagonists-We measured biliary mass and proliferation in our WT and $\mathrm{Mdr}^{-/-}$ mice treated chronically with saline, H1HR antagonist, H2HR antagonist or combined H1HR/H2HR antagonists. Further, our work has demonstrated that H1HR increases small, but not large, IBDM whereas H2HR enhances large, but not small, IBDM (16). Therefore, we evaluated the effects of blocking H1HR, H2HR or combination of H1HR/H2HR on small and large cholangiocyte proliferation and IBDM. Immunohistochemistry was performed for $\mathrm{Ki}-67$ to detect proliferating cholangiocytes and CK-19 staining was used to evaluate IBDM $(6,7,16)$.

\section{Detection of collagen deposition, fibrosis and HSC activation in Mdr2-/- mice treated with $\mathbf{H} 1$ or $\mathbf{H} 2 \mathbf{H R}$ antagonists-WT and $\mathrm{Mdr}^{-/-}$mice treated with H1HR or H2HR blockers, or combined H1HR/H2HR blockers, were evaluated for liver fibrosis by staining for Masson's Trichrome and Fast Green/Sirius Red, and by real-time PCR for fibronectin-1 and collagen type-1a $(6,7)$. To determine if H1HR or H2HR inhibition (or a combination of both) alters HSC activation we measured the expression of synaptophysin- 9 (SYP-9) by immunofluorescence and real-time PCR $(6,7)$.}

\section{Assessment of tumor growth and cholangiocyte proliferation in CCA-Nu/nu} mice were evaluated for tumor growth and proliferation. Tumor measurements were taken $3 \mathrm{x}$ a week using an electronic caliper in nu/nu mice. Volume of tumor mass was calculated as previously described by us $(12,13,15)$. In excised tumors, PCNA gene expression was measured by real-time PCR and immunohistochemistry was performed for Ki-67 to detect cholangiocyte proliferation.

Evaluation of angiogenesis, vascular alterations and EMT in CCA-In excised tumors from nu/nu mice treated with saline, H1HR or H2HR blockers and in human samples from control or CCA patients, we evaluated angiogenesis and vascular cell activity by real- 
time PCR for VEGF-A and immunohistochemistry and immunofluorescence for Von Willebrand Factor (vWF), respectively (6). EMT was evaluated by immunohistochemistry for CK-7, vimentin and E-Cadherin in tumors from nu/nu treated mice (saline, H1HR or H2HR antagonist) and human samples from control or CCA patients (13).

In vitro studies-To determine which specific cell type is involved in the action mediated by H1HR or H2HR, we performed in vitro studies in normal mouse cholangiocytes (Pool MSE chol), immortalized small mouse cholangiocytes (Small MSE chol), immortalized large mouse cholangiocytes (Large MSE chol), human CCA (Mz-ChA-1) cells, human HSCs (hHSCs) and cultured mast cells (MC/9 (ATCC ${ }^{\circledR}$ CRL-8306 ${ }^{\mathrm{TM}}$ ). All cells were maintained and cultured as described $(15,16,22)$. Cells were treated with vehicle $(0.1 \%$ BSA), mepyramine $(25 \mu \mathrm{M})$ or ranitidine $(25 \mu \mathrm{M})$ for $6-72$ hours for specific experiments outlined below.

\section{Determination of cholangiocyte proliferation and evaluation of CCA proliferation, angiogenesis and EMT following treatment with H1HR or H2HR inhibitors, in vitro-Cholangiocytes were treated with H1HR or H2HR antagonists and proliferation was measured by MTS assay and BrdU incorporation $(15,16,22)$.}

Similar to our in vivo studies, we performed experiments to determine the effects of blocking either H1HR or H2HR on CCA proliferation by MTS assay, and angiogenesis and EMT by real-time PCR. CCA cells were treated for up to 24 hours with vehicle, mepyramine or ranitidine prior to MTS assay and real-time PCR. Invasion was measured using a commercially available kit following vehicle, H1HR or H2HR antagonist treatment. The QCM ECMatrix Cell Invasion Assay was purchased from EMD Millipore (Billerica, MA) and used per manufacturer's instructions (13).

Detection of H1HR and H2HR expression in hHSCs, and assessment of hHSC activation following treatment with $\mathrm{H} 1 \mathrm{HR}$ or H2HR inhibitors, in vitro-To determine if hHSCs express the H1HR or H2HR we performed reverse-transcription PCR and real-time PCR, and compared expression levels to cultured mast cells and cholangiocytes, which express H1HR and H2HR (16). To evaluate whether H1HR or H2HR antagonism mediates hHSC activation, we took hHSCs treated with vehicle, mepyramine, or ranitidine and measured the mRNA levels of collagen type-1a by real-time PCR.

\section{Evaluation of the synergistic effects between mast cells, cholangiocytes and} CCA cells-Since mast cells infiltrate during PSC, increasing fibrosis, and are upregulated during CCA, we evaluated the synergistic effects of mast cells treated with H1HR or H2HR blockers on cholangiocytes and CCA cells. Mast cells were treated with vehicle, mepyramine or ranitidine and supernatants were collected and stored at $-80^{\circ} \mathrm{C}$.

In our first experiments, cholangiocytes were treated with collected mast cell supernatants and proliferation was measured by MTS assay and BrdU incorporation. Next, CCA cells were treated with mast cell supernatants collected following treatment with vehicle, mepyramine, or ranitidine and we evaluated proliferation, angiogenesis and EMT as detailed above. 


\section{Determination of the signaling pathways mediating small and large cholangiocyte and CCA function-In vitro, Small MSE chol and Large MSE chol} were treated with vehicle, histamine $(10 \mu \mathrm{M})$, forskolin $(25 \mu \mathrm{M})$, mepyramine or ranitidine prior to evaluating $\mathrm{IP}_{3}$ and $\mathrm{cAMP}$ levels using the $\mathrm{IP}_{3}$ kit from CisBio US, Inc. (Bedford, MA) and the Cyclic AMP ELISA Kit (Cayman Chemical; Ann Arbor, MI), respectively. In tumors from nu/nu mice treated with vehicle or H1HR and H2HR antagonists, we evaluated the Notch/Jagged signaling pathway by immunohistochemistry.

\section{Statistical Methods}

All data is expressed as mean \pm SEM. Groups were analyzed by the Student unpaired $t$ test when two groups are analyzed or a two-way ANOVA when more than two groups are analyzed, followed by an appropriate post hoc test. $\mathrm{p}<0.05$ was considered significant.

\section{Results \\ Chronic treatment with H1HR or H2HR blockers ameliorates hepatic damage in Mdr2-/- mice, but has no detrimental effect in WT mice}

By $\mathrm{H} \& \mathrm{E}$ we found that long-term usage of H1HR or H2HR antagonists had no negative effects on WT mice. However, in Mdr2 $2^{-/}$mice treated with either the H1HR antagonist, H2HR antagonist, or H1HR/H2HR antagonist combination, the degree of lobular damage, necrosis and inflammation was reduced compared to $\mathrm{Mdr} 2^{-/-}$mice treated with saline (Supplemental Figure 1).

\section{$\mathrm{H} 1$ and H2 HR expression is increased in PSC and cholangiocarcinoma}

By immunohistochemistry, we found that, in WT mice, H1HR expression was absent in both small and large cholangiocytes; however, following injury ( $\mathrm{Mdr}^{-/-}$mice) H1HR expression was increased in both small and large cholangiocytes, with a more profound increase in small cholangiocytes (Figure 1A). H2HR expression was absent in small cholangiocytes and slightly present in large cholangiocytes in WT mice; however, $\mathrm{Mdr} 2^{-/-}$mice showed a significant increase in H2HR expression in large cholangiocytes, but not small cholangiocytes (Figure 1A). Additionally, we found that the expression of H1HR and H2HR is upregulated in human PSC (Figure 1B), human CCA (demonstrated in tumors from saline-treated nu/nu mice (Figure 1C) and human CCA arrays (Figure 1D)) compared to controls.

\section{Mast cell activation and the $\mathrm{HDC} / \mathrm{HA}$ axis are reduced in $\mathrm{Mdr2}^{-/-}$mice treated with $\mathrm{H} 1 \mathrm{HR}$ or H2HR inhibitors}

We found that mast cell activation is decreased in Mdr2 $2^{-/}$mice (shown by mMCP-1 staining) and nu/nu mice (shown by toluidine blue staining) treated with H1HR or H2HR antagonists (Figures 2A and 2B). Further, mast cell markers were significantly decreased in $\mathrm{Mdr} 2^{-/-}$mice and tumors from nu/nu mice treated with either H1HR or H2HR antagonists (Figures 2C and 2D).

HDC expression was increased in Mdr2 $2^{-/}$mice, nu/nu mice and human PSC and CCA (Figures 3A, 3B and 3C); however, when $\mathrm{Mdr}^{-/-}$mice or nu/nu mice were treated with 
H1HR or H2HR antagonists the expression of HDC significantly decreased (Figures 3A and 3B). We have previously demonstrated that histamine levels increase in PSC (7) and here we found that histamine serum levels were decreased in both $\mathrm{Mdr} 2^{-/-}$mice (Figure 3D) and nu/nu mice (Figure 3E) treated with either H1HR or H2HR blockers compared to saline treatment. Further, histamine serum levels also increased in patients with CCA compared to controls (Figure 3F).

\section{Biliary proliferation and IBDM are significantly reduced following treatment with either H1HR or H2HR blockers}

We found that long-term usage of H1HR or H2HR antagonists had no effect on IBDM or biliary proliferation in WT mice (Figure 4A and 4B). Biliary proliferation and IBDM were significantly downregulated in Mdr2 ${ }^{-/}$mice following chronic exposure to either H1HR or H2HR inhibitors, or H1HR/H2HR antagonist combination (Figure 4A and 4B). Treatment with H1HR reduced small cholangiocyte proliferation, whereas H2HR inhibition reduced large cholangiocyte proliferation demonstrating that these receptors have differential action during biliary damage (Supplemental Figure 2). Combination treatment with both the H1HR and H2HR antagonists decreased both small and large cholangiocyte proliferation in Mdr2 ${ }^{-/}$mice when compared to saline treated mice (Supplemental Figure 2).

\section{Mdr2-/--associated fibrosis, collagen deposition and HSC activation decrease following treatment with H1HR or H2HR inhibition}

Fast Green/Sirius Red staining and semi-quantification (Figure 5A and Supplemental Figure 3A) as well as Masson's Trichrome (Figure 5B) reveal a decrease in collagen deposition in Mdr $2^{-/-}$mice treated with H1HR or H2HR antagonists or the combination of the two when compared to saline treated mice. WT mice treated with either H1HR or H2HR blockers had no visible change in collagen deposition as shown in Figure 5A. The expression of fibronectin and collagen type-1a is significantly reduced in $\mathrm{Mdr} 2^{-/-}$mice treated with either $\mathrm{H} 1 \mathrm{HR}$ or H2HR antagonists, or combined H1HR/H2HR antagonist treatment when compared to saline (Supplemental Figure 3B and 3C). HSC activation was decreased in $\mathrm{Mdr}^{-/-}$mice treated with either H1HR or H2HR antagonists, or combined H1HR/H2HR antagonist treatment when compared to saline treated mice as shown by immunofluorescence for SYP-9 (Figure 5C) and real-time PCR (Supplemental Figure 3D).

\section{Treatment with H1HR or H2HR antagonist did not affect HSC activation, in vitro}

We found that hHSCs express H1HR, but have minimal expression of H2HR, when compared to cultured mast cells and cholangiocytes (Supplemental Figure 4A-B). However, when hHSCs were treated with either the H1HR or H2HR antagonist there was no change in collagen type-1a expression (Supplemental Figure 4C), indicating that HR antagonism does not directly affect HSC activation. We conclude that H1HR or H2HR antagonism directly modulates biliary proliferation and activation, which in turn, mediates HSC activation and subsequent liver fibrosis. 


\section{Treatment with H1HR or H2HR antagonist decreases tumor growth in nu/nu mice}

Tumor volume significantly increased over time when nu/nu mice were treated with saline, whereas treatment with either H1HR or H2HR blunted tumor growth beginning at day 13 and continuing throughout the treatment (Figure 6A). In tumors from nu/nu mice treated with saline, PCNA expression was significantly upregulated, but was reduced in nu/nu mice following treatment with either H1HR or H2HR antagonists (Figure 6B) and Ki-67 positive cholangiocytes were reduced following treatment with either H1HR or H2HR antagonists (Figure 6C).

\section{H1HR and H2HR inhibition decreases angiogenesis and reverses EMT in human CCA}

In nu/nu mice treated with saline, the expression of $\mathrm{vWF}$ was increased; however, treatment with H1HR or H2HR blockers decreased vWF expression in nu/nu mice tumors (Figure 7A). VEGF-A expression increased in nu/nu mice treated with saline, but was significantly reduced in mice treated with either H1HR or H2HR antagonists (Figure 7B). With regards to EMT, in nu/nu mice, CK-7 and E-Cadherin were upregulated in tumors from nu/nu mice treated with H1HR or H2HR antagonists compared to tumors from mice treated with saline, while the expression of vimentin was dramatically reduced demonstrating a shift and reversal in EMT progression during CCA following H1HR or H2HR inhibition (Figure 7C). To verify our findings in human CCA, we found that the expression of vWF was increased in human CCA (Supplemental Figure 5) and with respect to EMT, the epithelial markers, CK-7 and E-Cadherin were increased in human CCA along with vimentin (mesenchymal marker) expression demonstrating that these cells are vascular and potentially entering EMT switch (Supplemental Figure 5).

\section{Treatment with H1HR or H2HR antagonist decreases cholangiocyte and CCA proliferation and CCA invasion, angiogenesis and EMT, in vitro}

Cholangiocyte proliferation is reduced following treatment with either H1HR or H2HR antagonists compared to vehicle treatment (Supplemental Figure 6). Similarly, CCA proliferation, invasion and $\mathrm{vWF}$ expression decreased after treatment with either H1HR or H2HR antagonists (Supplemental Figure 7A, 7B and 7C). The expression of E-Cadherin increased in CCA cells treated with either H1HR or H2HR antagonists compared to vehicle treatment (Supplemental Figure 7D).

\section{Synergistic effects of mast cells, cholangiocytes and CCA, in vitro}

Mast cells were pre-treated with either 0.1\% BSA (vehicle) or the H1HR or H2HR antagonists and supernatants were collected (Supplemental Figure 8A). Mast cell supernatants were then used to stimulate either cholangiocytes or Mz-ChA-1 cells for up to 72 hours (Supplemental Figure 8). Co-culture experiments revealed that when mast cells were pre-treated with $0.1 \%$ BSA (basal), cholangiocyte and CCA proliferation increased; however, both cholangiocyte and CCA proliferation decreased following treatment with mast cells plus H1HR or H2HR antagonist treatment as shown by BrdU incorporation and MTS assay (Supplemental Figure 8A - 8C).

Similar to our previous work, inhibition of $\mathrm{H} 1 \mathrm{HR}$ decreased histamine-stimulated $\mathrm{IP}_{3}$ levels in small cholangiocytes (Supplemental Figure 9A), but did not alter large cholangiocyte $\mathrm{IP}_{3}$ 
levels (not shown). When large cholangiocytes were treated with forskolin (which increases cAMP levels (23)) intracellular cAMP levels dramatically increased that were blocked with treatment with the H2HR antagonist (Supplemental Figure 9B). Inhibition of H2HR had no significant effect on small cholangiocyte intracellular cAMP levels (not shown). In nu/nu mice, treatment with $\mathrm{NaCl}$ increased Notch $1 / 2$ and Jagged 1 as shown by immunohistochemistry (Supplemental Figure 10) and treatment with either the H1HR or the H2HR antagonist decreased the expression of these factors (Supplemental Figure 10).

\section{Discussion}

Our study demonstrates a new use for readily available drugs that inhibit histamine receptors, which may be therapeutically beneficial to ameliorate both PSC and CCA progression. Both H1HR and H2HR inhibitors, and combined H1HR/H2HR antagonist treatment, successfully reversed liver damage, biliary ductular reaction, liver fibrosis and inflammation in $\mathrm{Mdr} 2^{-/}$mice, and no detrimental effects were found in WT mice. In addition, mice implanted with xenograft tumors and treated with either H1HR or H2HR antagonists displayed blunted tumor growth, decreased vascular angiogenesis and a reversal of EMT. Our novel findings show that inhibition of histamine signaling via receptor antagonism alleviates features of both PSC and CCA.

Numerous studies provide a link between PSC and CCA and it is well known that patients with PSC have an increased risk of developing CCA, especially if the PSC is diagnosed late or they are not responsive to therapy $(9,24,25)$. Further, large duct PSC more commonly develops into a malignant state versus small duct PSC (25). In support of this, we found that both small and large IBDM and cholangiocyte proliferation increased in $\mathrm{Mdr} 2^{-/-}$mice; however, the increase in large was higher than small suggesting that there is a critical role for large bile ducts during PSC damage. Further, we found that large IBDM was significantly increased in $\mathrm{Mdr} 2^{-/}$mice and treatment with the H2HR antagonist decreased large IBDM, whereas the H1HR blocker targeted small cholangiocyte proliferation. Combination treatment inhibited both small and large biliary proliferation and ductal mass. This is supportive of our previous work demonstrating that these receptors have specific targets in the biliary tree (16) and further investigation of their effects is warranted including studies using a combination of both H1HR and H2HR antagonists.

Recently, it has been reported that PSC patients have a 5 to $20 \%$ greater lifetime risk of developing CCA versus other general populations (24). Additionally, it has been demonstrated that the overall risk for CCA increases over 160-fold when comparing PSC patients to the general population (26). Besides CCA, PSC patients are at a greater risk of developing gallbladder cancer, pancreatic cancer and colorectal malignancies (24). Our work supports the hypothesis that enhanced histamine levels or mast cell markers may be potential biomarkers for early detection of both PSC and CCA.

The histamine/HR axis is a critical regulator of biliary damage and repair $(13,15,16,21)$. Treatment with H1HR or H2HR agonists increases biliary proliferation and induces proliferation in normal rats, and when immunocompromised mice were implanted with xenograft tumors and treated with histamine, tumor growth significantly increased $(15,16)$. 
Our previous work shows that inhibition of HDC using a-methyl-dl-histidine decreases BDL-induced damage and CCA progression $(15,22)$. We found that stimulation of H3HR decreased BDL-related proliferation and CCA growth and in a separate study we found that usage of the H4HR agonist, clobenpropit, significantly blunted tumor growth and reversed EMT associated with CCA $(13,21)$. Taken together, histamine is a potent trophic agent that induces biliary damage, tumor growth and hepatic fibrosis via HR interaction. Specifically, we note that the anti-fibrotic effects of histamine are mediated via biliary proliferation and activation, which in turn modulates HSC activation and fibrogenesis. Thus, we propose that histamine indirectly effects HSC activation, even though HSCs express both the H1HR and H2HR.

For our studies we utilized a dose of $10 \mathrm{mg} / \mathrm{kg} \mathrm{BW}(18,19)$ for both H1HR and H2HR antagonists (and in our combination treatment) and delivered drugs every day for 4 weeks to recapitulate a chronic usage. Human dosing for different H1HR and H2HR blockers ranges from $10 \mathrm{mg} /$ day to $180 \mathrm{mg} /$ day. For example, the standard dosing for ranitidine in humans is $300 \mathrm{mg} /$ day divided into two doses, but the maximum dose listed is as much as $6 \mathrm{~g} / \mathrm{day}$ (www.epocrates.com). Ranitidine dosing for children is typically between 4 and $10 \mathrm{mg} / \mathrm{kg}$ BW/day (www.pdr.net). Our dose is well within the maximum dose of $85.7 \mathrm{mg} / \mathrm{kg}$ BW/day. Most importantly, at this dosage we were able to significantly reverse many of the damaging features of both PSC and CCA including fibrosis and tumor growth.

In our current study, treatment with H1HR or H2HR blockers reduced mast cell activation along with decreasing histamine levels, thereby ameliorating PSC or CCA-induced damage. In relation to PSC, which is characterized by increased fibrosis and collagen deposition, it has been shown that mast cells induce fibroblast proliferation and collagen synthesis (28), supporting our current study. Mast cells play a detrimental role in tumor formation, growth and metastasis during pancreatic cancer, colorectal cancer and gastric cancer to name a few (29-31). Extensive studies have found that hepatocellular cancer and CCA can be driven by increased histamine levels and mast cell activation (28). Our study reveals that inhibition of HRs decreases mast cell activation leading to decreased tumor growth and angiogenesis along with a reversal of EMT. In endothelial cells, mast cell inhibition using cromolyn sodium improved the efficacy of anti-angiogenic therapy suggesting a mechanism of combining mast cell inhibitors and anti-growth factor inhibitors to decrease tumor burden (32).

We also found an upregulation of both $\mathrm{H} 1 \mathrm{HR}$ and $\mathrm{H} 2 \mathrm{HR}$ in $\mathrm{Mdr}^{-/-}$mice and nu/nu mice tumors as well as in human PSC and CCA. In support of this, the expression of both HRs has been found to be upregulated in intestinal tissue samples from irritable bowel syndrome (IBS) patients, a syndrome from which $~ 70 \%$ of PSC patients suffer (33). Further, increased H1HR activation induces an increase in inflammation, whereas the H2HR was found to decrease inflammation (33). Patients using ketotifen to block H1HR received relief from IBS symptoms including a reduction in abdominal pain; however, it was not clear if this drug also blocked mast cell activation (34). A separate study found that using ebastine, a secondgeneration H1HR antagonist, decreases visceral hypersensitivity and there is a current clinical trial that is ongoing to further explore the potential of ebastine in the treatment of IBS (35). Further, the H1HR has been found to be upregulated in human pediatric biliary 
atresia (BA) and histamine was also positively correlated with an increase in fibrosis in the livers from BA patients (36). To our knowledge, our studies are the first to explore the usage of HR antagonists in PSC-associated damage.

The H2HR inhibitor cimetidine has been shown to be a potential treatment for glioblastoma by reducing metastasis (37) and loxitidine treatment reduces gastric carcinogenesis (38). In support of our current findings, it has been shown that blocking H1HR inhibits colony growth in pancreatic cancer cells, in vitro (39) and blocking H2HR may inhibit cell proliferation, migration and induce apoptosis in colorectal cancer (40).

Our data demonstrate that intracellular signaling mediates histamine-regulated biliary proliferation as shown by our in vitro studies demonstrating that blocking H1HR decreases small cholangiocyte $\mathrm{IP}_{3}$ levels, whereas H2HR inhibition reduces large cholangiocyte cAMP signaling. These studies are consistent with our previous work showing that histamine alters small and large ductal reaction via independent signaling mechanisms (16). Further, we found alterations in the Notch/Jagged pathway in our studies using xenograft tumors. Both Notch and Jagged have been demonstrated to play a role in CCA regulation and tumor growth $(41,42)$. Wu, et al. recently demonstrated that Notch 1, 2 and 3 are important components in CCA proliferation and it's been demonstrated that inhibition of Notch 2 reduces tumor burden in both CCA and hepatocellular carcinoma $(41,42)$. We have found that, in HDC knockout mice subjected to $70 \%$ partial hepatectomy, Notch/Jagged signaling is altered (unpublished observations, Francis et al., 2016) suggesting that there is a link between histamine and Notch; however this requires further investigation.

In summary, we have demonstrated in different animal models and human samples that the H1HR and H2HR are important regulators of both PSC and CCA progression. Chronic usage of HR inhibitors revealed significant amelioration of pathologies associated with PSC and CCA including decreased (i) biliary damage, (ii) hepatic fibrosis, (iii) tumor growth, (iv) angiogenesis, and (v) EMT switch. With the significant gap in biomarkers and treatments for both PSC and CCA, we aimed to demonstrate that commonly used drugs might offer a benefit to both of these devastating diseases. In addition, elevated mast cell marker expression and/or increased histamine levels in patients presenting with suspicious symptoms could also represent potential biomarkers to identify disease pathology at an earlier stage. While we recognize that our choice of models don't necessarily mimic human disease exactly, we strongly believe that our data is important in understanding the pathogenesis of both PSC and CCA and our novel study implicates both H1HR and H2HR inhibition as promising targets in the quest towards a cure for PSC and CCA.

\section{Supplementary Material}

Refer to Web version on PubMed Central for supplementary material.

\section{Acknowledgments}

Financial support: Portions of this work were supported by (i) a VA Merit Awards (1I01BX003031, HF; 1I01BX001724, FM and 1I01BX002638, SD) from the United States Department of Veteran's affairs, Biomedical Laboratory Research and Development Service and R01 grants from NIH NIDDK (DK108959, HF and DK082435; 
SD); (ii) funds from the PSC Partners Seeking a Cure (HF \& SD); and (iii) a Baylor Scott and White Research Mentor Award (HF).

\section{Abbreviations}

a-SMA

ALT

AST

Brdu

CCA

CK-7

CK-19

$\Delta \Delta \mathrm{CT}$

EIA

EMT

FN-1

GAPDH

HA

HDC

hHSC

HR

HSC

IBDM

MC

$\mathrm{Mdr2}^{-/-}$

mMCP-1

MTS

PCNA

PSC

PCR

SYP-9 alpha-smooth muscle actin

alanine aminotransferase

aspartate aminotransferase

bromdeoxyuridine incorporation

cholangiocarcinoma

cytokeratin 7

cytokeratin-19

delta delta CT

enzyme immunoassay

$=$ epithelial mesenchymal transition

fibronectin-1

glyceraldehyde-3-phosphate dehydrogenase

histamine

1-histidine decarboxylase

human hepatic stellate cells

histamine receptor

hepatic stellate cell

intrahepatic bile duct mass

mast cell

multi-drug resistant knockout mouse

mouse mast cell protease-1

(3-(4,5-Dimethylthiazol-2-yl)-2,5-diphenyltetrazolium bromide, a yellow tetrazole)

proliferating cellular nuclear antigen

primary sclerosing cholangitis

quantitative polymerase chain reaction

synaptophysin-9

Hepatology. Author manuscript; available in PMC 2019 September 30. 


$\begin{array}{ll}\text { VEGF-A } & \text { vascular endothelial growth factor A } \\ \text { vWF } & \text { Von Willebrand Factor } \\ \text { WT } & \text { wild-type }\end{array}$

\section{References}

1. Bonato G, Cristoferi L, Strazzabosco M, Fabris L. Malignancies in Primary Sclerosing CholangitisA Continuing Threat. Dig Dis. 2015; 33(Suppl 2):140-148. [PubMed: 26641079]

2. Yimam KK, Bowlus CL. Diagnosis and classification of primary sclerosing cholangitis. Autoimmun Rev. 2014; 13:445-450. [PubMed: 24424180]

3. Gaudio E, Barbaro B, Alvaro D, Glaser S, Francis H, Ueno Y, Meininger CJ, et al. Vascular endothelial growth factor stimulates rat cholangiocyte proliferation via an autocrine mechanism. Gastroenterology. 2006; 130:1270-1282. [PubMed: 16618418]

4. Renzi A, Demorrow S, Onori P, Carpino G, Mancinelli R, Meng F, Venter J, et al. Modulation of the biliary expression of arylalkylamine $\mathrm{N}$-acetyltransferase alters the autocrine proliferative responses of cholangiocytes in rats. Hepatology. 2013; 57:1130-1141. [PubMed: 23080076]

5. Kennedy LL, Hargrove LA, Graf AB, Francis TC, Hodges KM, Nguyen QP, Ueno Y, et al. Inhibition of mast cell-derived histamine secretion by cromolyn sodium treatment decreases biliary hyperplasia in cholestatic rodents. Lab Invest. 2014; 94:1406-1418. [PubMed: 25365204]

6. Hargrove L, Kennedy L, Demieville J, Jones H, Meng F, DeMorrow S, Karstens W, et al. BDLinduced biliary hyperplasia, hepatic injury and fibrosis are reduced in mast cell deficient Kitw-sh mice. Hepatology. 2017

7. Jones H, Hargrove L, Kennedy L, Meng F, Graf-Eaton A, Owens J, Alpini G, et al. Inhibition of mast cell-secreted histamine decreases biliary proliferation and fibrosis in primary sclerosing cholangitis Mdr2-/- mice. Hepatology. 2016

8. Boberg KM, Lind GE. Primary sclerosing cholangitis and malignancy. Best practice \& research. Clinical gastroenterology. 2011; 25:753-764. [PubMed: 22117640]

9. Rizvi S, Eaton JE, Gores GJ. Primary Sclerosing Cholangitis as a Premalignant Biliary Tract Disease: Surveillance and Management. Clin Gastroenterol Hepatol. 2015; 13:2152-2165. [PubMed: 26051390]

10. Fickert P, Wagner M, Marschall HU, Fuchsbichler A, Zollner G, Tsybrovskyy O, Zatloukal K, et al. 24-norUrsodeoxycholic acid is superior to ursodeoxycholic acid in the treatment of sclerosing cholangitis in Mdr2 (Abcb4) knockout mice. Gastroenterology. 2006; 130:465-481. [PubMed: 16472600]

11. Trauner M, Fickert P, Baghdasaryan A, Claudel T, Halilbasic E, Moustafa T, Wagner M, et al. New insights into autoimmune cholangitis through animal models. Digestive diseases. 2010; 28:99-104. [PubMed: 20460897]

12. Johnson C, Huynh V, Hargrove L, Kennedy L, Graf-Eaton A, Owens J, Trzeciakowski JP, et al. Inhibition of Mast Cell-Derived Histamine Decreases Human Cholangiocarcinoma Growth and Differentiation via c-Kit/Stem Cell Factor-Dependent Signaling. Am J Pathol. 2016; 186:123-133. [PubMed: 26597881]

13. Meng F, Han Y, Staloch D, Francis T, Stokes A, Francis H. The H4 histamine receptor agonist, clobenpropit, suppresses human cholangiocarcinoma progression by disruption of epithelial mesenchymal transition and tumor metastasis. Hepatology. 2011; 54:1718-1728. [PubMed: 21793031]

14. Pusterla T, Nemeth J, Stein I, Wiechert L, Knigin D, Marhenke S, Longerich T, et al. Receptor for advanced glycation endproducts (RAGE) is a key regulator of oval cell activation and inflammation-associated liver carcinogenesis in mice. Hepatology. 2013; 58:363-373. [PubMed: 23504974]

15. Francis H, DeMorrow S, Venter J, Onori P, White M, Gaudio E, Francis T, et al. Inhibition of histidine decarboxylase ablates the autocrine tumorigenic effects of histamine in human cholangiocarcinoma. Gut. 2012; 61:753-764. [PubMed: 21873469] 
16. Francis HL, Demorrow S, Franchitto A, Venter JK, Mancinelli RA, White MA, Meng F, et al. Histamine stimulates the proliferation of small and large cholangiocytes by activation of both IP3/ $\mathrm{Ca} 2+$ and cAMP-dependent signaling mechanisms. Laboratory investigation; a journal of technical methods and pathology. 2012; 92:282-294. [PubMed: 22064319]

17. Boyce JA. The biology of the mast cell. Allergy and asthma proceedings: the official journal of regional and state allergy societies. 2004; 25:27-30.

18. Lawson JA, Adams WJ, Morris DL. Ranitidine and cimetidine differ in their in vitro and in vivo effects on human colonic cancer growth. Br J Cancer. 1996; 73:872-876. [PubMed: 8611398]

19. Watanabe N, Matsuda E, Masuda A, Nariai K, Shibasaki T. The effects of fexofenadine on eosinophilia and systemic anaphylaxis in mice infected with Trichinella spiralis. Int Immunopharmacol. 2004; 4:367-375. [PubMed: 15037214]

20. Kennedy L, Hargrove L, Demieville J, Bailey J, Dar W, Polireddy K, Chen Q, et al. Knockout of 1Histidine Decarboxylase Prevents Cholangiocyte Damage and Hepatic Fibrosis in Mice Subjected to High-Fat Diet Feeding via Disrupted Histamine/Leptin Signaling. Am J Pathol. 2017

21. Francis H, Onori P, Gaudio E, Franchitto A, DeMorrow S, Venter J, Kopriva S, et al. H3 histamine receptor-mediated activation of protein kinase Calpha inhibits the growth of cholangiocarcinoma in vitro and in vivo. Molecular cancer research: MCR. 2009; 7:1704-1713. [PubMed: 19825989]

22. Graf A, Meng F, Hargrove L, Kennedy L, Han Y, Francis T, Hodges K, et al. Knockout of histidine decarboxylase decreases bile duct ligation-induced biliary hyperplasia via downregulation of the histidine decarboxylase/VEGF axis through PKA-ERK1/2 signaling. Am J Physiol Gastrointest Liver Physiol. 2014; 307:G813-823. [PubMed: 25169977]

23. Francis H, Glaser S, Ueno Y, Lesage G, Marucci L, Benedetti A, Taffetani S, et al. cAMP stimulates the secretory and proliferative capacity of the rat intrahepatic biliary epithelium through changes in the PKA/Src/MEK/ERK1/2 pathway. J Hepatol. 2004; 41:528-537. [PubMed: 15464232]

24. Horsley-Silva JL, Rodriguez EA, Franco DL, Lindor KD. An update on cancer risk and surveillance in primary sclerosing cholangitis. Liver Int. 2017; 37:1103-1109. [PubMed: 28028930]

25. Karlsen TH, Boberg KM. Update on primary sclerosing cholangitis. J Hepatol. 2013; 59:571-582. [PubMed: 23603668]

26. Bergquist A, Ekbom A, Olsson R, Kornfeldt D, Loof L, Danielsson A, Hultcrantz R, et al. Hepatic and extrahepatic malignancies in primary sclerosing cholangitis. J Hepatol. 2002; 36:321-327. [PubMed: 11867174]

27. Jarido V, Kennedy L, Hargrove L, Demieville J, Thomson J, Stephenson K, Francis H. The emerging role of mast cells in liver disease. Am J Physiol Gastrointest Liver Physiol. 2017; 313:G89-G101. [PubMed: 28473331]

28. Hodges K, Kennedy L, Meng F, Alpini G, Francis H. Mast cells, disease and gastrointestinal cancer: A comprehensive review of recent findings. Transl Gastrointest Cancer. 2012; 1:138-150. [PubMed: 22943044]

29. Folkman J. Role of angiogenesis in tumor growth and metastasis. Semin Oncol. 2002; 29:15-18.

30. Horton KM, Abrams RA, Fishman EK. Spiral CT of colon cancer: imaging features and role in management. Radiographics. 2000; 20:419-430. [PubMed: 10715340]

31. Ribatti D, Guidolin D, Marzullo A, Nico B, Annese T, Benagiano V, Crivellato E. Mast cells and angiogenesis in gastric carcinoma. Int J Exp Pathol. 2010; 91:350-356. [PubMed: 20412338]

32. Wroblewski M, Bauer R, Cubas Cordova M, Udonta F, Ben-Batalla I, Legler K, Hauser C, et al. Mast cells decrease efficacy of anti-angiogenic therapy by secreting matrix-degrading granzyme B. Nat Commun. 2017; 8:269. [PubMed: 28814715]

33. Fabisiak A, Wlodarczyk J, Fabisiak N, Storr M, Fichna J. Targeting Histamine Receptors in Irritable Bowel Syndrome: A Critical Appraisal. J Neurogastroenterol Motil. 2017; 23:341-348. [PubMed: 28551943]

34. Klooker TK, Braak B, Koopman KE, Welting O, Wouters MM, van der Heide S, Schemann M, et al. The mast cell stabiliser ketotifen decreases visceral hypersensitivity and improves intestinal symptoms in patients with irritable bowel syndrome. Gut. 2010; 59:1213-1221. [PubMed: 20650926] 
35. Wouters MM, Balemans D, Van Wanrooy S, Dooley J, Cibert-Goton V, Alpizar YA, ValdezMorales EE, et al. Histamine Receptor H1-Mediated Sensitization of TRPV1 Mediates Visceral Hypersensitivity and Symptoms in Patients With Irritable Bowel Syndrome. Gastroenterology. 2016; 150:875-887e879. [PubMed: 26752109]

36. Zhou K, Xie G, Wen J, Wang J, Pan W, Zhou Y, Xiao Y, et al. Histamine is correlated with liver fibrosis in biliary atresia. Dig Liver Dis. 2016; 48:921-926. [PubMed: 27257052]

37. Lefranc F, Yeaton P, Brotchi J, Kiss R. Cimetidine, an unexpected anti-tumor agent, and its potential for the treatment of glioblastoma (review). Int J Oncol. 2006; 28:1021-1030. [PubMed: 16596218]

38. Takaishi S, Cui G, Frederick DM, Carlson JE, Houghton J, Varro A, Dockray GJ, et al. Synergistic inhibitory effects of gastrin and histamine receptor antagonists on Helicobacter-induced gastric cancer. Gastroenterology. 2005; 128:1965-1983. [PubMed: 15940630]

39. Cricco GP, Mohamad NA, Sambuco LA, Genre F, Croci M, Gutierrez AS, Medina VA, et al. Histamine regulates pancreatic carcinoma cell growth through $\mathrm{H} 3$ and $\mathrm{H} 4$ receptors. Inflamm Res. 2008; 57(Suppl 1):S23-24. [PubMed: 18345506]

40. Jiang CG, Liu FR, Yu M, Li JB, Xu HM. Cimetidine induces apoptosis in gastric cancer cells in vitro and inhibits tumor growth in vivo. Oncol Rep. 2010; 23:693-700. [PubMed: 20127008]

41. Huntzicker EG, Hotzel K, Choy L, Che L, Ross J, Pau G, Sharma N, et al. Differential effects of targeting Notch receptors in a mouse model of liver cancer. Hepatology. 2015; 61:942-952. [PubMed: 25311838]

42. Kwon H, Song K, Han C, Zhang J, Lu L, Chen W, Wu T. Epigenetic Silencing of miRNA-34a in Human Cholangiocarcinoma via EZH2 and DNA Methylation: Impact on Regulation of Notch Pathway. Am J Pathol. 2017; 187:2288-2299. [PubMed: 28923203] 


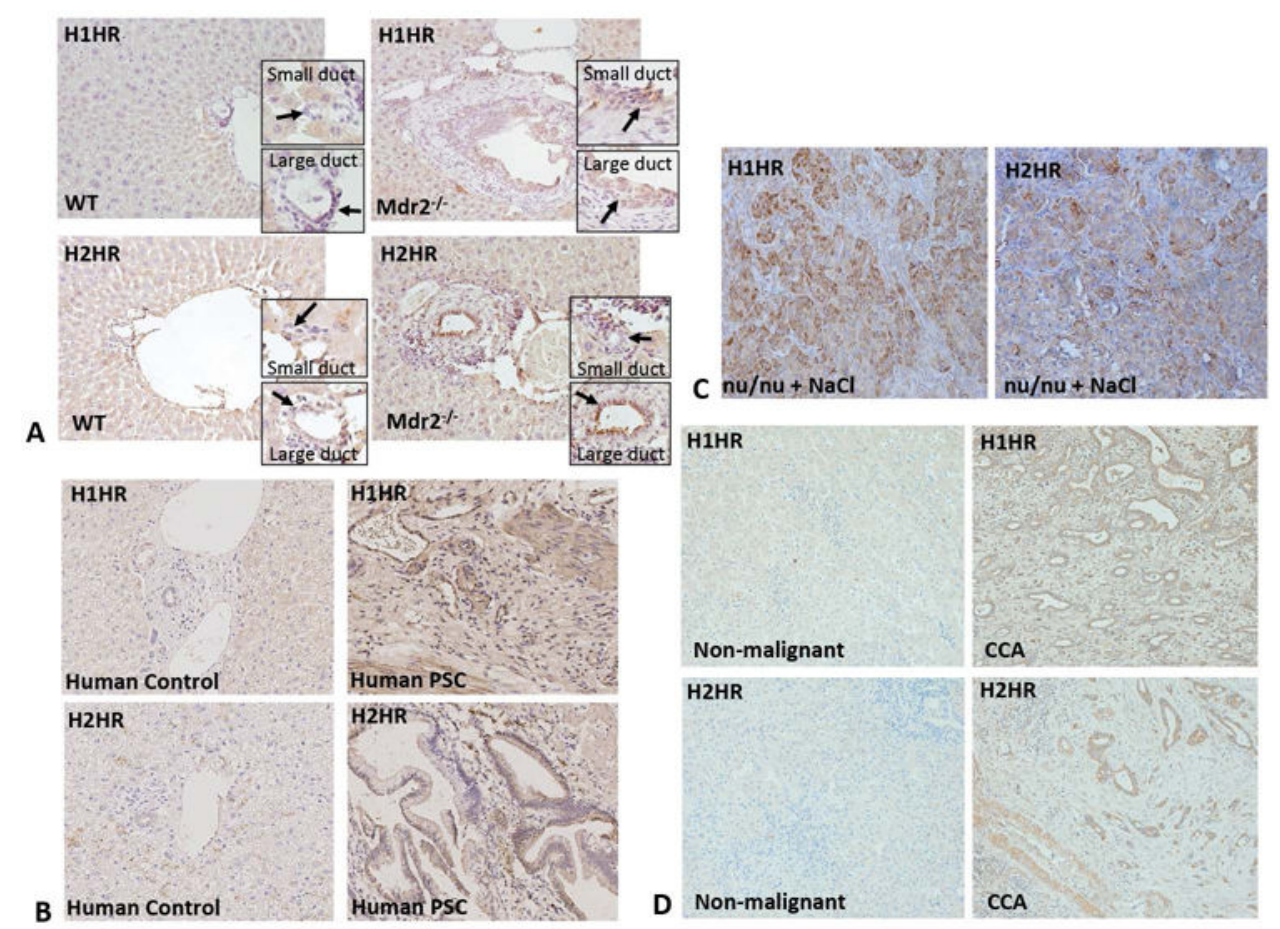

Figure 1.

The expression of H1HR and H2HR in Mdr2-/- mice, nu/nu mice, and human PSC and CCA. Immunohistochemistry for $\mathrm{H} 1 \mathrm{HR}$ and $\mathrm{H} 2 \mathrm{HR}$ was performed in liver sections from WT, Mdr2-/- mice, nu/nu mice, human control and human PSC. H1HR expression was found in both small and large ducts of $\mathrm{Mdr} 2^{-/-}$mice (but not in WT mice), with a more pronounced expression small (A). In WT mice, H2HR expression was low in large bile ducts, but absent in small bile ducts; however, in Mdr2-/- mice, H2HR expression was increased in large bile ducts, but not small (A). R Both $\mathrm{H} 1$ and $\mathrm{H} 2 \mathrm{HR}$ are expressed at low levels in human control liver sections, but the expression of $\mathrm{H} 1$ and $\mathrm{H} 2 \mathrm{HR}$ are increased in human PSC compared to controls (B). Tumors from nu/nu mice treated with saline expressed increased levels of H1HR and H2HR, particularly in CCA cells versus stromal cells (C). Both $\mathrm{H} 1$ and H2 HR are expressed at low levels in human non-malignant liver sections, but expression of both of these receptors is increased in human CCA when compared to non-malignant controls (D). Representative images are $20 \mathrm{X}$ magnification. 

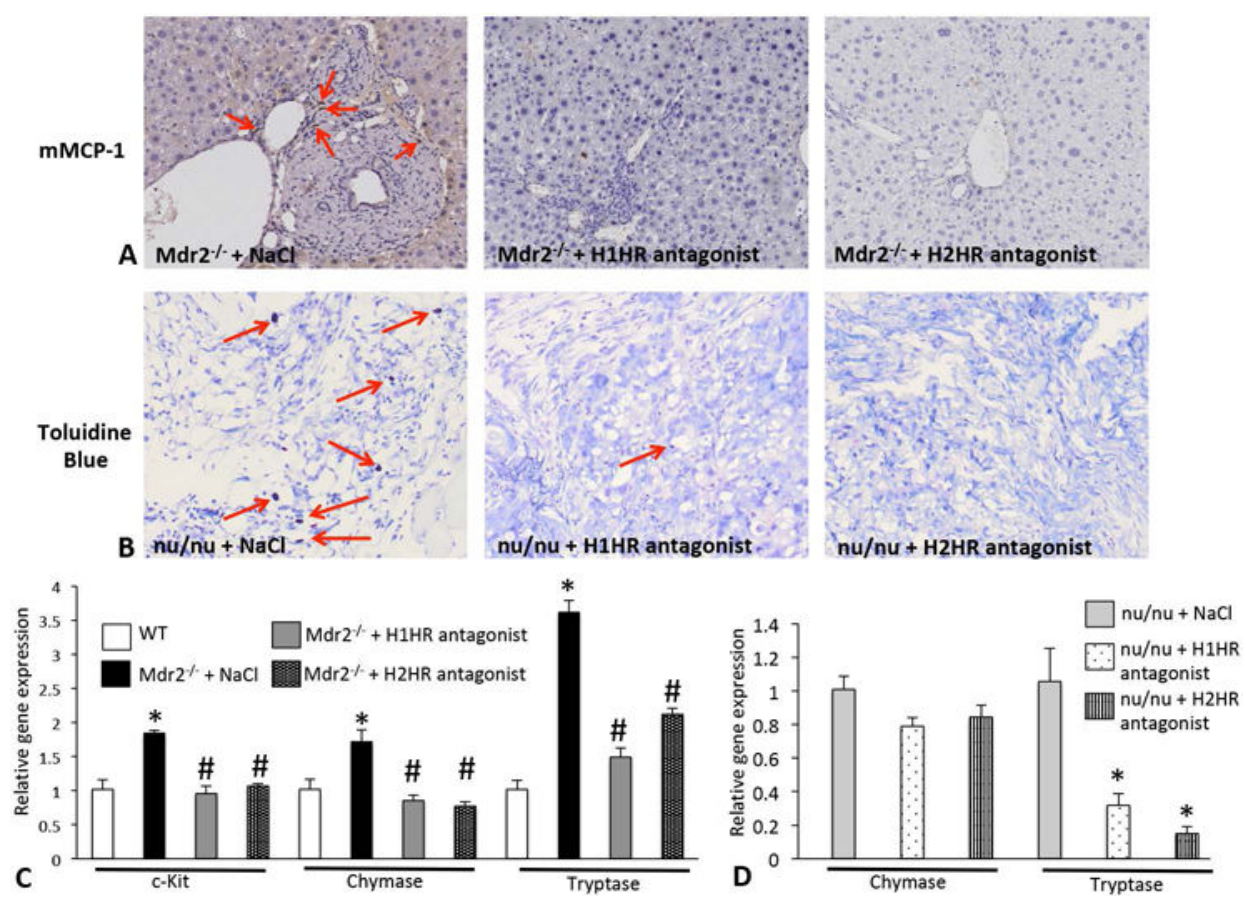

Figure 2.

Mast cell expression in Mdr2 ${ }^{-/-}$mice and nu/nu mice. Mast cells were detected by $\mathrm{mMCP}-1$ immunohistochemistry in $\mathrm{Mdr} 2^{-/-}+$saline and $\mathrm{Mdr} 2^{-/-}$mice treated with either H1HR or H2HR antagonists (A). Mdr2 ${ }^{-/}$mice treated with saline displayed numerous mast cells surrounding bile ducts (as shown by the red arrows), whereas the inhibition of either H1HR or H2HR via antagonist treatment ablated the infiltration of mast cells when compared to $\mathrm{Mdr} 2^{-/-}+$saline (A). Toluidine blue staining was performed in tumors from nu/nu mice treated with saline, H1HR or H2HR antagonist to detect mast cell number (B). In nu/nu mice treated with saline there were numerous infiltrating mast cells (as shown by the red arrows), and treatment with either an H1HR or H2HR antagonist decreased mast cell number when compared to nu/nu + saline (B). Mast cell activation was detected by qPCR for c-Kit, chymase and tryptase in total liver from WT, Mdr2 $2^{-/}+$saline and $\mathrm{Mdr} 2^{-/-}$mice treated with H1HR or H2HR antagonist (C) and in tumors from nu/nu mice treated similarly (D). The expression of mast cell markers was significantly increased in $\mathrm{Mdr} 2^{-/}+$saline mice when compared to WT, but the expression of these markers was decreased in Mdr2 ${ }^{-/-}$ treated with either H1HR or H2HR antagonist when compared to saline treated (C). The expression of chymase was not significantly decreased in nu/nu mice treated with the H1HR or the H2HR antagonist; however, tryptase levels were significantly decreased in nu/nu mice treated with either antagonist antagonist when compared to saline treated (D). Data are mean \pm SEM of 9 experiments for real-time PCR. ${ }^{*} \mathrm{p}<0.05$ versus WT; \# $<<0.05$ versus $\mathrm{Mdr} 2^{-/-}$ saline treatment. Representative images are 20X magnification. 

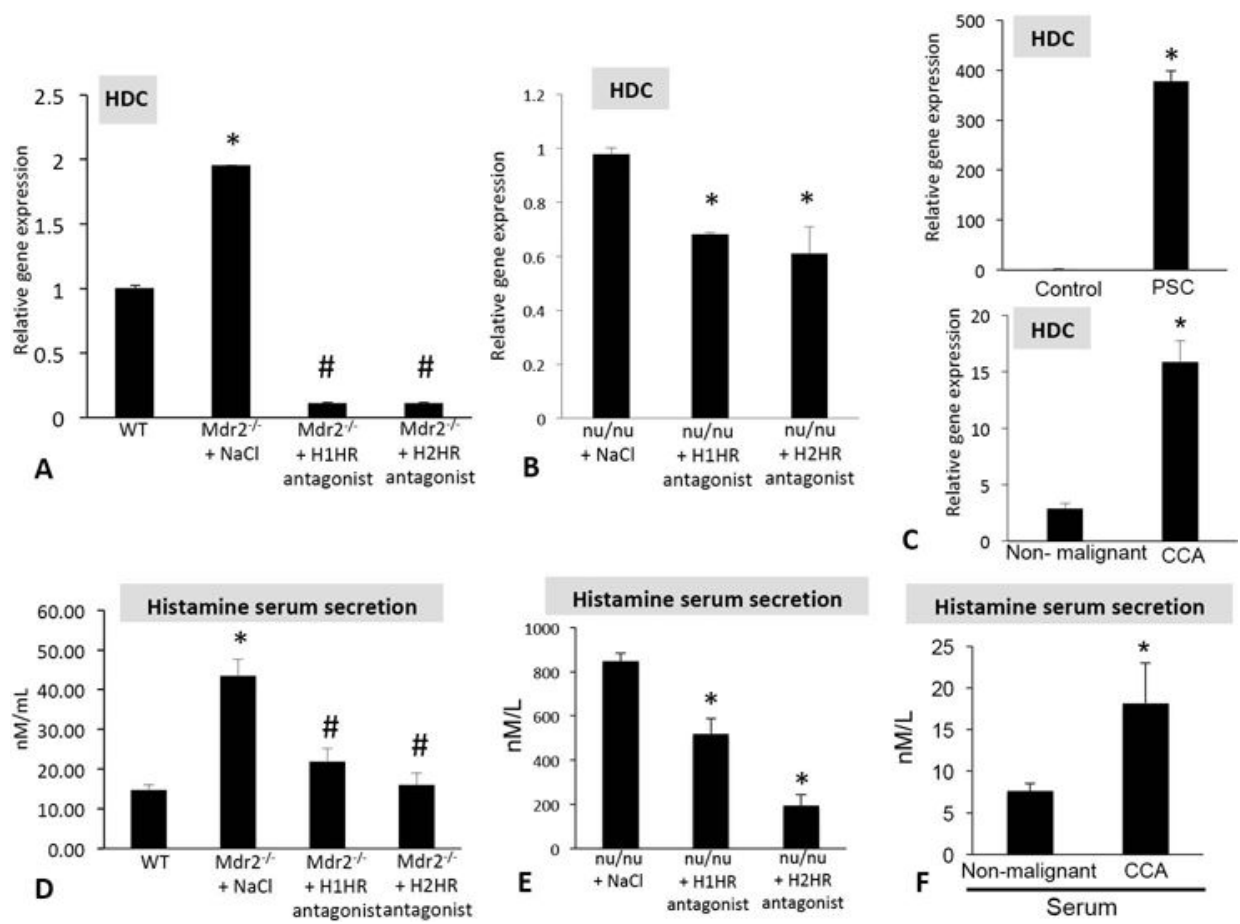

Figure 3.

Evaluation of the HDC/histamine axis in Mdr2-/- mice, nu/nu mice, and human PSC and CCA. The hepatic expression of HDC is increased in $\mathrm{Mdr} 2^{-/-}$mice treated with saline when compared to WT, but expression is decreased in mice treated with either H1HR or H2HR antagonist when compared to saline treated (A). HDC expression is decreased in tumors from nu/nu mice treated with the H1HR or the H2HR antagonist when compared to saline treated (B). Hepatic HDC expression increased in human PSC and CCA compared to controls (C). Histamine secretion increased in serum from $\mathrm{Mdr}^{-/-}$saline treated mice compared to WT, but histamine secretion was reduced in $\mathrm{Mdr} 2^{-/-}$mice treated with the H1HR or H2HR antagonist when compared to saline treated (D). Serum histamine levels were decreased in nu/nu mice treated the H1HR and $\mathrm{H} 2 \mathrm{HR}$ antagonist when compared to saline treated (E). Histamine secretion increased in human CCA compared to non-malignant controls $(F)$. Data are mean \pm SEM of 12 experiments for real-time PCR and at least 10 experiments for EIA. ${ }^{*} \mathrm{p}<0.05$ versus WT, control or non-malignant; $\# \mathrm{p}<0.05$ versus $\mathrm{Mdr} 2^{-/-}$saline treatment. 


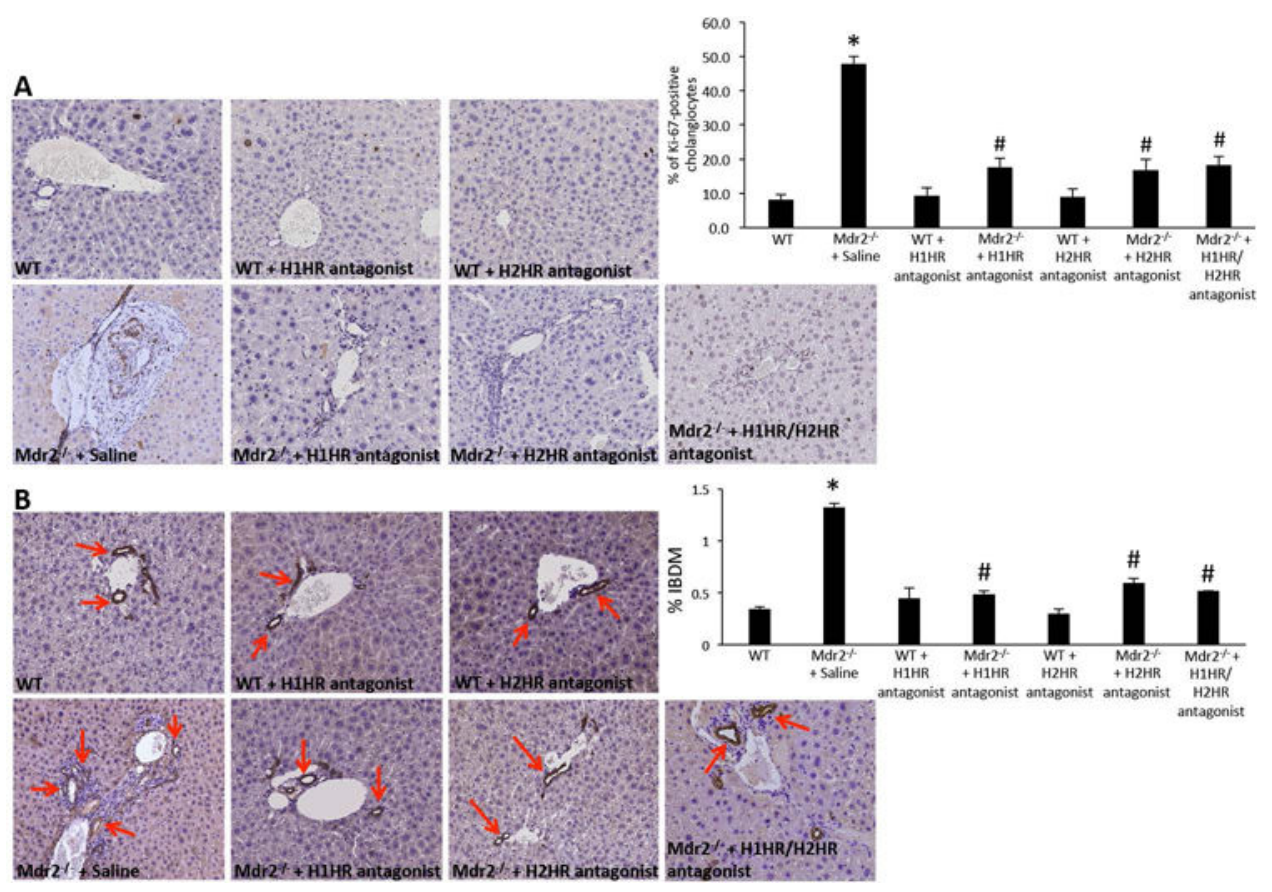

Figure 4.

Measurement of biliary proliferation and IBDM in $\mathrm{Mdr}^{-/-}$mice. Biliary proliferation is unchanged in WT mice treated with either H1HR or H2HR antagonists when compared to saline treated WT (A). However, biliary proliferation is increased in $\mathrm{Mdr} 2^{-/-}$mice treated with saline when compared to WT, but was reduced in $\mathrm{Mdr}^{-/-}$mice following chronic treatment with either H1HR or H2HR antagonists when compared to saline treated (A). Similarly, IBDM was unchanged in WT treated with H1HR, H2HR or H1HR/H2HR antagonist when compared to saline treated WT (A). IBDM increased in Mdr2 ${ }^{-/-}$mice treated with saline when compared to WT, but was significantly decreased in $\mathrm{Mdr} 2^{-/-}$mice following administration of $\mathrm{H} 1 \mathrm{HR}, \mathrm{H} 2 \mathrm{HR}$ or $\mathrm{H} 1 \mathrm{HR} / \mathrm{H} 2 \mathrm{HR}$ antagonist when compared to saline treatment (B). Data are mean \pm SEM of 12 cumulative experiments from 6-8 mice per group. ${ }^{*} \mathrm{p}<0.05$ versus WT; $\# \mathrm{p}<0.05$ versus $\mathrm{Mdr}^{-/-}$saline treatment. Representative mages are $20 \mathrm{X}$ magnification. 


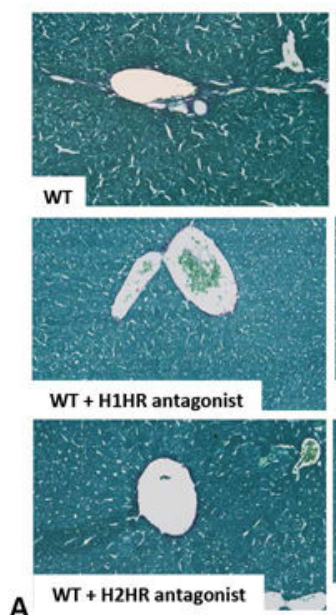

A

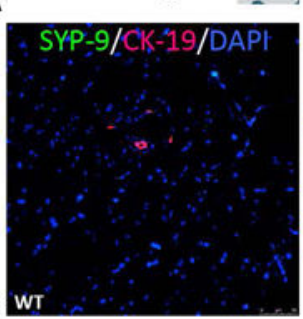

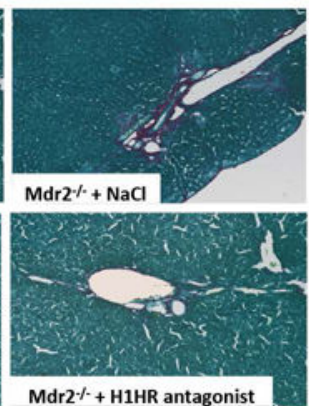

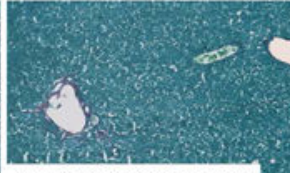

$\mathrm{Mdr} 2 \%+\mathrm{H} 2 \mathrm{HR}$ antagonist $\%$

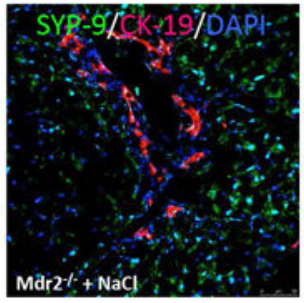

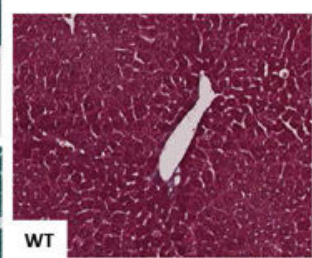
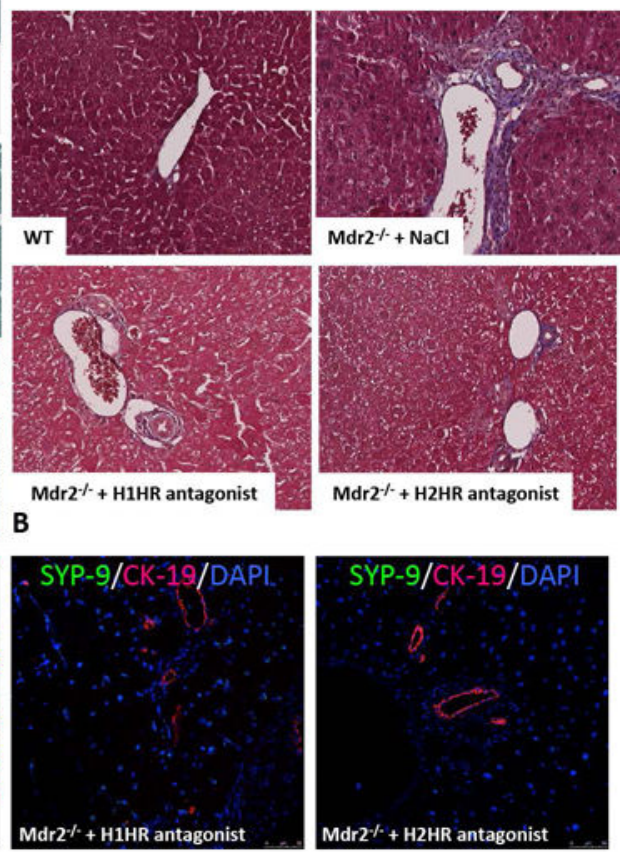

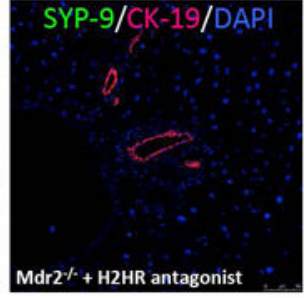

Figure 5.

Assessment of hepatic fibrosis in WT and $\mathrm{Mdr} 2^{-/-}$mice. In Mdr2 ${ }^{-/-}$mice treated with saline there was increased collagen content and bridging fibrosis (as shown by Sirius Red and Masson's Trichrome staining) when compared to WT mice; however, this was ameliorated in Mdr2 ${ }^{-/}$mice treated with either H1HR or H2HR antagonist when compared to saline treated mice (A and B). WT mice treated with H1HR or H2HR antagonists displayed little to no collagen deposition as shown by Sirius Red (A). HSC activation was measured by SYP-9 (green) immunofluorescence co-stained with CK-19 (red) to image bile ducts (C). There was an increase in activated HSCs in Mdr2 ${ }^{-/}$mice treated with saline when compared to WT mice, which was ablated in Mdr2 ${ }^{-/}$mice treated with either H1HR or H2HR antagonist when compared to saline treated mice (C). Representative images are 20X for colorimetric staining and 20X for immunofluorescence. 

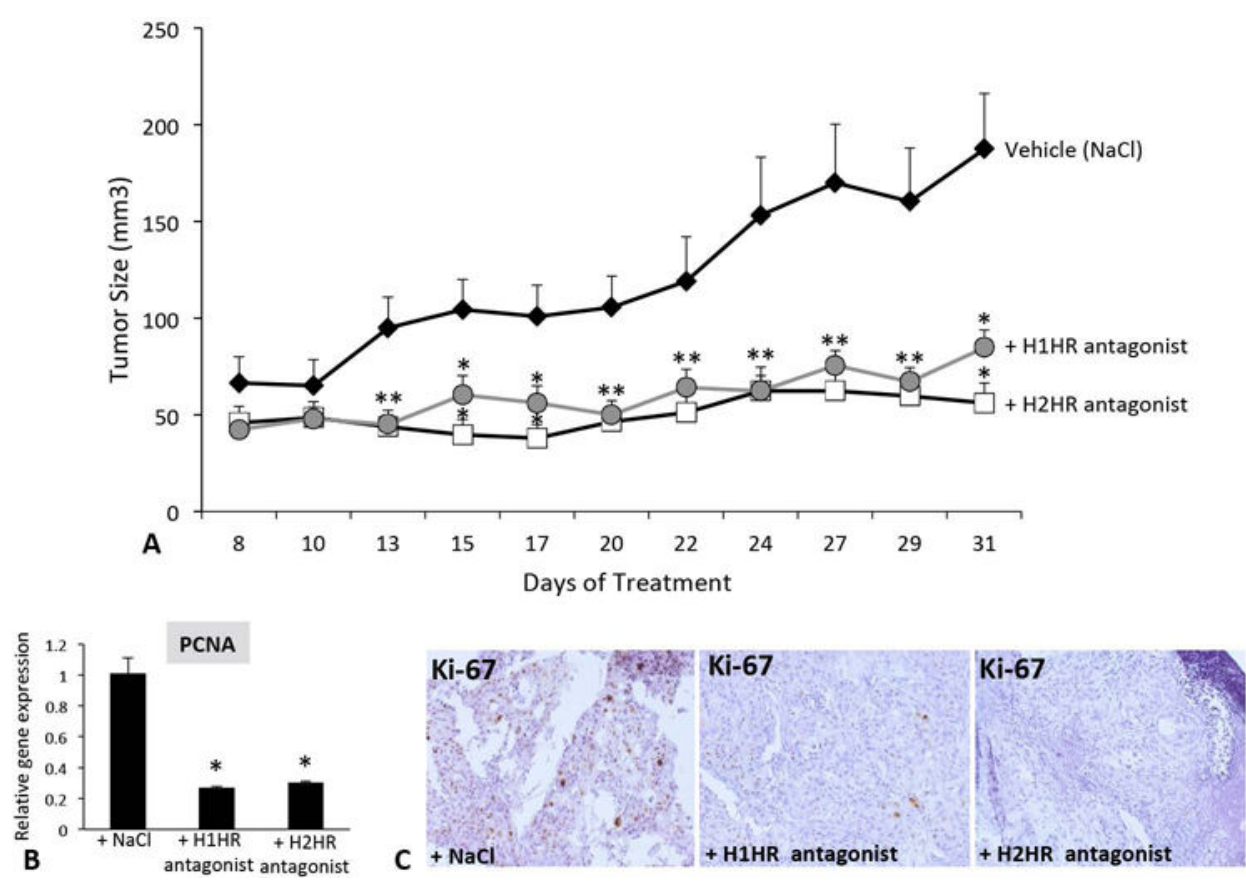

Figure 6.

Tumor growth and proliferation evaluation in nu/nu mice. Tumor growth was measured in $\mathrm{nu} / \mathrm{nu}$ mice treated with $\mathrm{NaCl}$, the $\mathrm{H} 1 \mathrm{HR}$ or the $\mathrm{H} 2 \mathrm{HR}$ antagonist following tumor establishment (A). Tumors were measured every other day for 31 days. Growth of tumors significantly increased in nu/nu mice treated with saline beginning at day 13 and continued throughout the experiment (A). Nu/nu mice treated with either H1HR or H2HR antagonists had blunted tumor growth throughout the treatments compared to $\mathrm{NaCl}$-treated mice (A). PCNA gene expression decreased in tumors from nu/nu mice treated with either H1HR or H2HR antagonists compared to saline treatment (B) and Ki-67 staining was reduced in tumors from nu/nu mice treated with $\mathrm{H} 1 \mathrm{HR}$ or $\mathrm{H} 2 \mathrm{HR}$ antagonists compared to saline treatment (C). Data are mean \pm SEM of 6 experiments for real-time PCR. *p<0.05 versus saline treatment. Representative images are 20X magnification. 


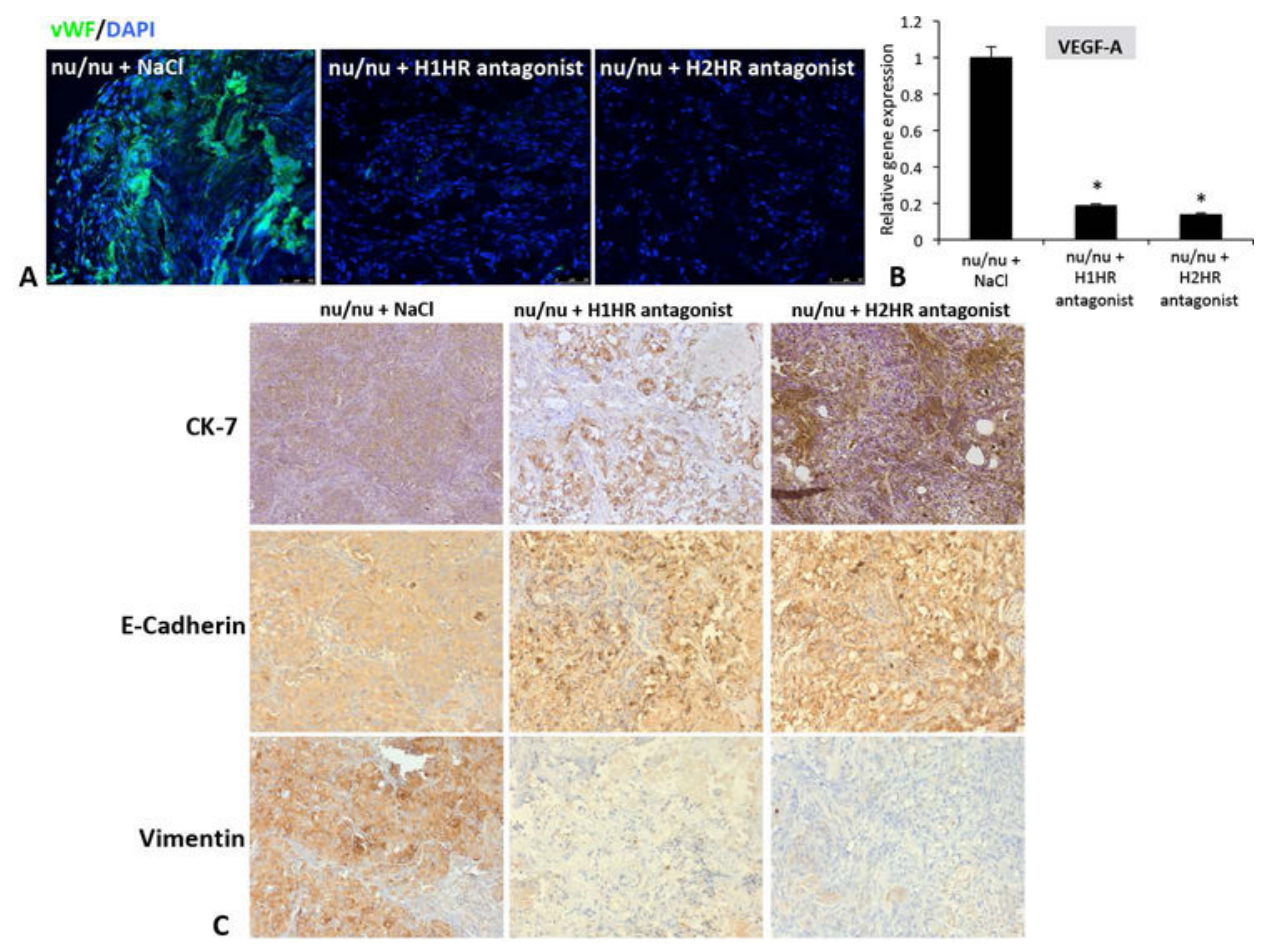

Figure 7.

Effect of angiogenesis and EMT in nu/nu mice. vWF (green) expression was highly upregulated in tumors from saline-treated nu/nu mice, but was reduced in tumors from nu/nu mice treated with either H1HR or H2HR antagonist (A). VEGF-A gene expression was measured in isolated tumors by real-time PCR, and nu/nu mice treated with either H1HR or H2HR antagonist had significantly less VEGF-A expression compared to nu/nu mice treated with saline (B). The expression of CK-7 and E-Cadherin increased in tumors from nu/nu mice treated with either the H1HR or the H2HR antagonist compared to saline treatment $(\mathrm{C}$, top and middle panels). In contrast, the mesenchymal marker, vimentin was reduced in tumors from mice treated with $\mathrm{H} 1 \mathrm{HR}$ or $\mathrm{H} 2 \mathrm{HR}$ antagonist compared to saline treated mice (C, bottom panels). Data are mean \pm SEM of 12 experiments for real-time PCR. ${ }^{*} \mathrm{p}<0.05$ versus saline treatment. Images are 20x magnification. 